given up by the water. To cool one pound of wate from 212 to 32 degrees, 180 B.t.u. must be taken from the water. But, to boil one pound at 32 degrees into steam at 212 degrees will require

180 B.t.u. +970.4 B.t.u. $=1,150.4$ B.t.u.

Remember that this is above $92 \mathrm{deg}$. Fahr. and not above the thermometer zero or the absolute zero.

Notice that the steam is no hotter than the water from which it was produced after the water reached 212 degrees, although it took over 5.3 times as much heat to turn it into steam as it did to raise its temperature from 32 degrees to 212 degrees.

The mercury in a thermometer placed in the wate while it was being heated from 32 to 212 degrees, or the boiling point, would have risen from 32 to 212 degrees. You could see the water getting hotter; the thermometer would show that it was absorbing heat. But, after 212 degrees had been reached, and, although heat were still applied to the water, a thermometer would not still applied to the water, a thermometer would not
show any increase in temperature even though all the show any increase in temperature even though all the water was boiled into steam, and we know that over five times as much heat was needed to make steam of the water as was necessary to get the water ready to make steam. Neither would a thermometer show that it required any additional heat to melt ice at 32 degrees into water at 32 degrees, or any removal of heat to coo water at 32 degrees into ice at the same temperature.

We have just considered the two kinds of heat know as sensible and latent heat. Sensible heat was that amount of heat applied to the water to raise its temperature from 32 to 212 degrees or the temperature a which steam began to form. It was sensible, i. e., it was apparent to the senses; in this case, the sense of sight when we saw the mercury rise in the thermometer. The relative amounts of these two kinds of heat eter. The relative

The heat required to make steam of the water at 21 degrees was not apparent to the senses, except that we could see the steam escape as it was made, but we could not detect the added heat by the aid of a thermomete or by feeling the water. The heat was latent, and that is what is meant when latent heat of vaporization is

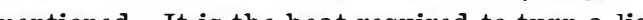
mentioned. It is the heat gas without change of temperature. To boil int steam a pound of water at 32 degrees, then, requires
180 B.t.u. of sensible heat and 970.4 B.t.u. of latent heat, or a total of 1,150 B.t.u. And this latter amount is

\section{The Calculation of the Condenser Dielectric Constant}

\section{By Kenneth Richardson}

I WISH to make a condenser of a certain capacity for my wireless transmitter or receiver. Someone ha kindly directed me to use the following formula:

$C$ in micro-farads $=0.0000002247 \times \frac{k a}{x}$

In which $a$ is the combined area in square inches of one side of all the sheets of dielectric between plates,

$x$ is the average thickness in inches of the dielectrics between plates; and

is the dielectric constant.

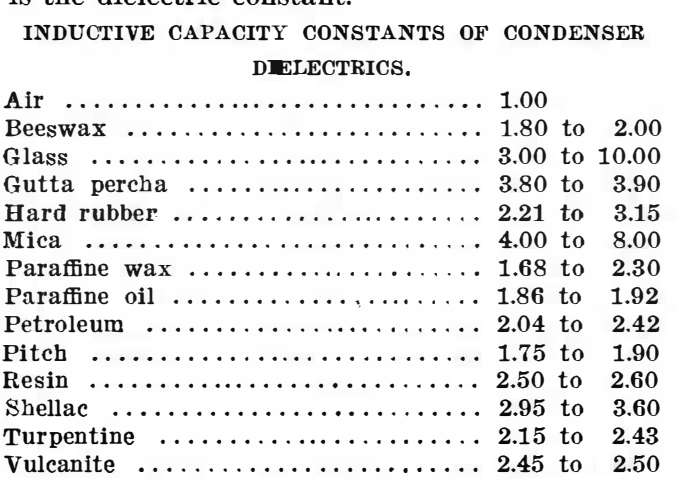

In referring to a table of dielectric constants it is found that $k$ is quite an indefinite quantity. For example, the constant of glass varies between 3 and 10 , depending upon the quality. The dielectric constant cannot be known by the appearance of the substance. This is an electrical property of the substance and electrical means must be employed in order to arrive at its value.

For a certain capacity, then, say 0.005 M. F., how may I know the size and number of sheets or plates to use, since $I$ do not know the exact dielectric constant of the material?

This is often the problem of those who design their own apparatus. Usually the dimensions are guessed at, resulting in an unbalanced outfit.

The method outlined will enable anyone with a wave meter to accurately calculate the dielectric constant of any insulator very easily.

Connect up the instruments comprising the closed circuit of the wireless transmitter in the usual manner. Adjust the helix for a certain wave, say 200 meters.

Our method of getting the dielectric constant is to make a small condenser of one or two plates of dielec- what is meant when total heat or total heat of the team is spoken of, as in the steam tables. Latent heat of fusion is the heat that must be taken from a liquid to make it solidify without change of temperature, a when water at $32 \mathrm{deg}$. Fahr. freezes into ice.

THE MECHANICAL EQUivalent OF HEa

If a one-pound weight fell from a shelf 778 feet from the ground, it would strike the ground with 778 foot pounds of energy. This number of foot-pounds is called the mechanical equivalent of heat, because with a perfect apparatus it would take the same amount of energy to raise the weight up to the shelf, as it would to raise the temperature of one pound of water $1 \mathrm{deg}$. Fahr.

So, when it is desired to express heat energy in terms of mechanical energy, we have

\section{Heat energy or B. t. u. $=\frac{\text { mechanical energy }}{778}$}

If a steam plant could use all the heat in the coal it received, then all of this heat would be converted into work at the engine shaft. Thus, from a pound of coa containing 14,500 heat units per pound, we would get $14,500 \times 778=11,281,000$ foot-pounds

mechanical energy.

The plant makes use of but very little of all the heat in the coal. The boiler, if handled well, will advantageously use, say, 80 per cent, or

$$
14,500 \times 0.80=11,600 \text { B.t.u. }
$$

Now of this the engine, which we will assume is a goo compound condensing one, will turn into work, say, 19 per cent of all the heat it receives, which in this case we assume to be 11,600 B.t.u. for each pound of coal burned in the boiler.

$$
11,600 \times 0.19=2,204 \text { B.t.u. }
$$

For each pound of coal burned containing 14,500 B.t.u. there is available at the engine shaft only 2,204 B.t.u. The amount of heat turned into useful work multiplied by 100 and divided by the heat in the coal gives the percentage of the total available heat in the coal that was turned into work, or

$$
\frac{2204 \times 100}{14,500}=15.2 \text { per cent. }
$$

Ind this amount is called the thermal efficiency of the plant.

You cannot soak up as much water with a wad of paper as with a sponge of equal volume. Neither will a granite block soak up as much as an ordinary red brick. And so on with various substances; their capacities for absorbing liquids are not the same.

The capacities of different substances for absorbing heat vary in the same way. If you put one heat unit into a pound of water, which is at, say, 62 deg. Fahr., you raise its temperature one degree, or to $63 \mathrm{deg}$. Fahr. If you put the same amount of heat into a pound of silver, its temperature will increase $18.1 \mathrm{deg}$. Fahr., and for lead it would increase the temperature 33 degrees; for copper, 10.75 degrees; for ammonia, 0.99 degree, and so on, each substance having its own peculiar capacity for absorbing heat to produce a given rise in temperature. This is shown in Fig. 3. This capacity is called the specific heat of a substance, because that amount will produce a temperature change in a given substance that it will not produce on any other; it is specific for that substance. Specific heat, then, is the heat energy required to raise a unit weight of matter 1 degree as compared with the heat needed to raise a unit weight of water 1 degree.

In order to compare the heat required to produce an increase of 1 degree in some substance, we use water as a standard, for water is in common use and requires one heat unit to produce an increase of one degree; its specific heat is 1 , or unity. As used in engineering calculations, specific heat is a ratio; it expresses the relation that exists between two quantities, as

specific heat $=$ heat required to raise $1 \mathrm{lb}$. of matter $1 \mathrm{deg}$. heat required to raise $1 \mathrm{lb}$. of water $1 \mathrm{deg}$. APPLICATION OF SPECIFIC HEAT.

In engineering it often is important to know how much heat is required to increase the temperature of a substance one degree, to know its specific heat.

For example, it is desired to know how much heat is carried away by the flue gases per pound of fuel burned. The specific heat of flue gas is generally taken as 0.24 ; i. e., it takes 0.24 B.t.u. to heat a pound of flue gas one degree. So to find the heat lost in the flue gases, we multiply the weight of gas made by a pound of fuel by the specific heat, or 0.24 , and then multiply this product by the difference in temperature between the gases leaving the boiler and the air entering the furnace. The same general method applies for finding the amount of heat absorbed or given up by any substance. tric to be tested, this sample condenser to be substituted for the standard condenser in the closed circuit and the effect upon the wave-length noted on the meter. We can then know the exact capacity of the sample condenser, and from this know the dielectric constant by employing the simple formulas to follow.

It is necessary to get the exact inductance of the closed circuit part of helix which was adjusted for 200 meters wave. The helix inductance is found by the formula :

$$
L \text { in micro-henries }=\frac{101.5 \times N^{2} r}{1 \times 1000}
$$

In which $N$ is the exact number of turns in circuit,

$r$ is the radius of the helix in inches, and

$l$ is the exact height in inches of the helix (effective turns in circuit only).

Let us assume a helix inductance of $10 \mathrm{M}$. $\mathrm{H}$.

We now have both the wave-length and inductance of the circuit.

The sample condenser is now made and substituted care being taken to have voltage of the spark coil on transformer reduced so as not to puncture the sample dielectric.

A very tiny spark is all that is necessary for the test Without disturbing adjustment of helix, operate coil and take a new reading on the wave meter. Let us assume the new reading to be 50 meters.

With the known inductance (10 M. H.) and the known wave-length (50 meters), the exact capacity of the sample condenser is found by the formula:

$$
C \text { in micro-farads }=\left\{\frac{W}{1885 \sqrt{\times} L}\right\}^{2}
$$

In which $W$ is the wave-length in meters, and $L$ is the inductance in micro-henries.

From this, our capacity is 0.000068 plus M. F.

When we know the exact capacity of the sample conand the measurement is take

From these data, the exact dielectric constant is found by the formula:

\section{$K=\frac{C x}{0.0000002247 \times a}$}

In which $C$ is the capacity in micro-farads

$x$ is the average thickness in inches of the dielectric, and

$a$ is the total area in square inches of one side of the een plates.

In the formulas it must be kept in mind that: (a) The capacity of a group of individual condensers in multiple is equal to the sum of the individual capacities.

(b) The capacity of a group of individual condensers in series is,

$$
C=\begin{array}{llll}
\frac{1}{C_{1}} & \frac{1}{C_{2}} & \text { plus } \frac{1}{C_{3}} & \text { plus; } \text { etc. }
\end{array}
$$

In which $C_{1}, C_{2}, C_{3}$, etc., are the individual capacities and $C$ is the joint capacity.

(c) Long connecting wires to condenser, spark gap, and helix will make the calculations inaccurate. It is advisable to employ all the helix or helices available for the tests.

(d) The open circuit should be entirely disconnected during the readings.

(e) Intense brush discharge from the edges of a condenser increase the capacity, throwing the calculations off. Avoid extreme high voltage.

The Cost of Building the Panama Canal THE widely published official figures of the cost of the Panama Canal have possibly given the general public an exaggerated idea of the cost of the canal as a piece of engineering work. The statement has been made that the entire cost of the canal to the United States when completed will be in the neighborhood of $\$ 400,000,000$, and it is a natural conclusion that the bulk of this expenditure has gone into the work of digging the canal and constructing the locks.

It will surprise many engineers even, we doubt not, to learn from figures published in the last number of the "Canal Record," that up to March 31st, 1914, the entire expenditure on the canal in the Department of Construction and Engineering had been only \$204,087,000. The total expense up to the same date for all purposes connected with the canal was $\$ 322,659,000$. The chief items in the account, apart from construction and engineering, were in round numbers, civil administration, $\$ 7,000,000$; sanitation, $\$ 17,000,000$; fortifications, $\$ 5,000,000$, and general items, $\$ 90,000,000$. Under this latter head are included the payment of $\$ 40$,000,000 to the French Canal Company and $\$ 10,000,000$ to the Republic of Panama. There is also included under this head very heavy expenditures for the reconstruction of the Panama Railroad, the construction and repair of buildings and the cleaning up of the cities of Colon and Panama.-Engineering News. 